\title{
Lo sguardo e la voce: dialogo e convergenze nel Novecento francese, a cura di Giuliana Costa Ragusa e Luciana Grasso
}

\section{Emanuele Kanceff}

\section{(2) OpenEdition}

\section{Journals}

Edizione digitale

URL: http://journals.openedition.org/studifrancesi/9650

DOI: $10.4000 /$ studifrancesi.9650

ISSN: 2421-5856

\section{Editore}

Rosenberg \& Sellier

\section{Edizione cartacea}

Data di pubblicazione: 1 décembre 2007

Paginazione: 693

ISSN: 0039-2944

\section{Notizia bibliografica digitale}

Emanuele Kanceff, «Lo sguardo e la voce: dialogo e convergenze nel Novecento francese, a cura di Giuliana Costa Ragusa e Luciana Grasso», Studi Francesi [Online], 153 (LI | III) | 2007, online dal 30 novembre 2015, consultato il 08 janvier 2021. URL: http://journals.openedition.org/studifrancesi/9650 ; DOI: https://doi.org/10.4000/studifrancesi.9650

Questo documento è stato generato automaticamente il 8 janvier 2021.

\section{cc) (†) $\odot$}

Studi Francesi è distribuita con Licenza Creative Commons Attribuzione - Non commerciale - Non opere derivate 4.0 Internazionale. 


\title{
Lo sguardo e la voce: dialogo e convergenze nel Novecento francese, a cura di Giuliana Costa Ragusa e Luciana Grasso
}

\author{
Emanuele Kanceff
}

\section{NOTIZIA}

AA. VV., Lo sguardo e la voce: dialogo e convergenze nel Novecento francese, a cura di Giuliana COSTA RAGUSA e Luciana GRASso, Palermo, S.F. Flaccovio editore, 2006, pp. 230 (Coll.

«Lingua e Testo», 4).

1 I numerosi contributi raccolti in questo volume non hanno lo scopo di puntare l'attenzione su un particolare argomento o una precisa corrente critica o scuola poetica, né su una modalità interpretativa specifica: essi presentano, a giro di orizzonte, personaggi, tematiche, oggetti che hanno in comune soltanto il fatto di essere appartenuti al Novecento. In tal modo si affiancano poeti e artisti, cineasti e musicisti, con punti di vista critici differenti, nella comune idea della ricerca del rinnovamento, nel confronto anche stridente dei dinamismi creativi. Nell'impossibilità di seguire uno a uno i numerosi discorsi critici, ci limitiamo a segnalare al lettore i contenuti salienti del volume, che vanno da Green a Crevel alla statua animata, dalla "belle noiseuse" alla "femme fatale", da Malika Mokeddem a Perec, senza dimenticare Malraux, Bonnefoy e persino Flaubert. Eccone, comunque il dettaglio. Annie BRUDO, Pardelà le miroir: "Histoire de Ralph" de Julien Green - Pietro CANCELLIERE, "Babylone": spazi linguistici dell'immaginario creveliano - Enrico CASTRONOvo, La statua animata da Mérimée a Cocteau: fluttuazioni e occorrenze di un mito - Giuliana cosTA RAGUSA, Pittura/scrittura: un dialogo ne "Le Ruban au cou d'Olympia" - Giusy DE LUCA, L'immagine filmica di "Jules et Jim" $e$ delle "Deux Anglaises et le continent": la letteratura dopo i film - Luciana GRASSO, "La belle 
noiseuse": da Balzac a Jacques Rivette - Bruna LO BIUNDO, Le porte del surreale. Percorsi della femme fatale nella Parigi antropomorfa degli anni venti - Vito PECORARO, "L'Interdite" di Malika Mokeddem: dall'immaginario alla conquista di uno spazio identitario - Florence PELLEGRINI, Espace mode d'emploi: l'esthétique tabulaire chez Flaubert et Perec - Elena PELLICCIOTTI, La percezione della realtà e l'etnologia nei "Noyers de l'Altenburg" di André Malraux - Simona POLliCINo, Tra linguaggio, immagine e realtà: Yves Bonnefoy e la parola poetica oltre la rappresentazione - Daniela TONONI, L'anamorfosi letteraria: un regard oblique su "La Disparition" di Georges Perec. 